\title{
Índices de desempenho zootécnico e econômico de sistemas de produção de leite com diferentes níveis tecnológicos
}

\section{Zootechnical and economic performance indexes of milk production systems with different technological levels}

\author{
Rodrigo de Andrade Ferrazza'; Marcos Aurélio Lopes²*; Flávio de Moraes 3 ; \\ Fábio Raphael Pascoti Bruhn ${ }^{4}$
}

\begin{abstract}
Resumo
Objetivou-se estimar índices de desempenho zootécnico e econômico de referência, analisar a influência de diferentes níveis tecnológicos sobre a rentabilidade da atividade leiteira e identificar os componentes que exerceram maiores representatividades sobre o custo total e operacional efetivo. Foram analisados 38 indicadores de tamanho, zootécnico e econômico de 61 sistemas de produção de leite, localizados em Minas Gerais e Rio de Janeiro, agrupados em função de três níveis tecnológicos. Os dados foram coletados durante o período de janeiro de 2002 a dezembro de 2011. Adotou-se a estrutura do custo operacional e do custo total como metodologia para apuração dos custos. Os resultados foram comparados pelo teste de ANOVA (distribuição normal), complementado pelo teste LSD, e pelo teste de Kruskal-Wallis (distribuição não normal), também complementado pelo teste LSD. A estratificação dos sistemas de produção em função do nível tecnológico pareceu não ser um bom critério para ser utilizado quando se deseja realizar comparações entre grupos distintos de produtores, evidenciado pela ausência de significância estatística $(\mathrm{P}>0,05)$ na comparação de índices de tamanho e zootécnico entre os grupos baixo e médio nível tecnológico. Os produtores de alto nível tecnológico fizeram investimentos sem as devidas análises de retorno sobre o investimento e risco. Os itens componentes do custo total e operacional efetivo que exerceram maiores representatividades foram, em ordem decrescente, alimentação e mão de obra.
\end{abstract}

Palavras-chave: Análise de rentabilidade, custo de produção, índices de referência, lucratividade, pecuária leiteira

\begin{abstract}
The objective of this study was to estimate reference zootechnical and economic performance indexes, examine the influence of different technological levels on technical and economic results on dairy farms and identify the components that had higher representativeness on total and effective operational cost. Thirty-eight size, zootechnical and economic indicators of 61 milk production systems, grouped according to three technological levels, were analyzed. The data were collected during January 2002 to December 2011 period. It was adopted the structure of the operating cost and the total cost as methodology for calculating the costs. The results were compared by ANOVA test (normal distribution), complemented by LSD test, and Kruskal-Wallis test (non-normal distribution), also complemented by
\end{abstract}

\footnotetext{
${ }^{1}$ Discente de Mestrado em Zootecnia da Universidade Federal de Lavras, UFLA, Lavras, MG. E-mail: rodrigoferrazza@yahoo. com.br

2 Prof. do Dept ${ }^{\circ}$ de Medicina Veterinária, UFLA, Lavras, MG. E-mail: malopes@dmv.ufla.br

3 Discente de Mestrado em Ciências Veterinárias, UFLA, Lavras, MG. E-mail: f.demoraes2009@gmail.com

${ }^{4}$ Discente de Doutorado em Ciências Veterinárias, UFLA, Lavras, MG. E-mail: fabio_rpb@yahoo.com.br

* Autor para correspondência
} 
LSD test. The stratification of milk production systems according to technological level does not seem to be a good criterion to be used when it wants to make comparisons between different groups of producers, evidenced by the lack of statistical significance $(\mathrm{P}>0.05)$ in comparing of size and zootechnical indexes between low and medium technological level groups. Producers of high technological level made investments without proper analysis of return on investment and risk. The items of total and effective operational cost that had higher representativeness were, in descending order, feeding and labor.

Key words: Dairy production, production cost, profitability, profitability analysis, reference indexes

\section{Introdução}

A produção de leite no Brasil está distribuída por todo o país e a heterogeneidade do processo produtivo é marcante, sendo constituída desde os produtores não especializados aos mais tecnificados, estabelecendo unidades de produção com diferentes níveis de tecnologia e produtividade. A despeito das limitações tecnológicas e gerenciais do setor primário, uma nova realidade tem surgido na atividade leiteira com a conscientização dos produtores sobre a necessidade de administrarem eficientemente o negócio, tornando-o mais competitivo e buscando maior rentabilidade. Segundo Ferreira, Ferreira e Ezequiel (2004), a eficiência no processo produtivo é um ponto fundamental para a manutenção de qualquer atividade pecuária, sendo que estudos com a finalidade de determinar o custo e a rentabilidade proporcionam aos produtores subsídios para a tomada de decisões.

$\mathrm{O}$ acompanhamento de índices zootécnicos e econômicos pode ser utilizado como ferramenta para o gerenciamento do desempenho técnico-econômico da atividade leiteira. Nesse contexto, Gomes e Alves (1999) mencionaram que uma boa forma de identificar se a atividade exercida é eficiente, ou não, é compará-la com a de outros rebanhos semelhantes (benchmarks). Com isso, tendo como referência os produtores mais eficientes, pode-se tentar eliminar as ineficiências. Por outro lado, o reconhecimento de elevada eficiência econômica de alguns rebanhos pode ser extremamente valioso, tornando-se referência para os demais (TUPY et al., 2003).
Diversos critérios de classificação dos sistemas de produção de leite podem ser adotados, cuja escolha depende dos objetivos propostos (FIGUEIREDO; GOMES, 2009). Dentre os fatores que podem influenciar o custo de produção, está o nível tecnológico do sistema de produção de leite. De acordo com Schiffler et al. (1999), a produção leiteira no mundo tem se elevado via inovação tecnológica. Madalena (2001) salientou que a pecuária leiteira rentável deve se basear em diversos componentes, dentre os quais citou o uso de instalações, máquinas e equipamentos, quando justificados economicamente. Carmo (1998) destacou, ainda, que tecnologias caras, embora excludentes aos agricultores familiares, dentro de certos limites de sua lógica, podem encontrar espaços, principalmente se apoiados nas diretrizes da sustentabilidade da produção agrícola. Portanto, o planejamento produtivo e o uso de tecnologia apropriada às diferentes regiões são essenciais para o sucesso financeiro da atividade (HADDADE et al., 2005).

Levando em consideração a grande heterogeneidade da cadeia produtiva do leite no Brasil, sua presença em todo o território nacional e o caráter dinâmico inerente ao ambiente de produção, a identificação, a quantificação e o estabelecimento de índices técnico-gerenciais e econômicos de referência são de interesse prático para o meio profissional, devendo ser considerados por gestores de empresas rurais e profissionais que trabalham com assistência técnica e extensão rural. A comparação entre os índices alcançados pelo produtor e os obtidos em diferentes sistemas de produção, considerando os 
fatores que sejam comuns entre os sistemas, pode possibilitar o embasamento para a elaboração de um planejamento, o estabelecimento de metas, a avaliação dos resultados e a tomada de decisões estratégicas.

Os objetivos deste trabalho foram avaliar a influência do nível tecnológico sobre os resultados técnicos e econômicos em fazendas produtoras de leite, estimar índices de desempenho zootécnico e econômico de referência, visando auxiliar técnicos e pecuaristas no suporte à tomada de decisões gerenciais, e identificar os componentes que exerceram maiores representatividades sobre $\mathrm{o}$ custo total e operacional efetivo.

\section{Material e Métodos}

Foram estimados e analisados os índices de tamanho, zootécnico e econômico de 61 sistemas de produção de leite localizados nas regiões central, sul e sudoeste de Minas Gerais e noroeste, norte e sul do Rio de Janeiro. A amostragem não probabilística por julgamento foi realizada considerando-se a disponibilidade e a qualidade dos dados por parte dos produtores.

A pesquisa considerou duas etapas diferentes no levantamento das informações. Em uma primeira etapa, utilizando-se um questionário e caderneta de campo, foi realizado o inventário completo dos bens das propriedades estudadas, apurando valor e vida útil de cada ativo, sendo, posteriormente, alocados em um dos seguintes grupos: benfeitorias, máquinas, veículos, equipamentos e implementos, ferramentas e rebanho. Nas situações nas quais o pecuarista não dispunha de informações referentes ao valor e data de aquisição, para a estimativa dos valores atuais, bem como da vida útil restante, foi adotado o critério proposto por Lopes et al. (2004). Quanto às benfeitorias, cada uma foi medida sendo atribuído um estado de conservação objetivando auxiliar na estimativa do valor atual. Em função da área, do estado de conservação e do padrão de acabamento foi estimado um valor por $\mathrm{m}^{2}$ de construção. $\mathrm{O}$ valor utilizado foi produto do valor do $\mathrm{m}^{2}$ pela área da benfeitoria (LOPES et al., 2004). $\mathrm{Na}$ outra etapa, as propriedades foram visitadas no início de cada mês para coleta de dados referentes às produções, despesas realizadas e receitas apuradas no mês anterior. A coleta de dados foi feita por meio de cadernetas de campo especificamente preparadas para esse fim. Os dados foram então cadastrados no software Custo Bovino Leite ${ }^{\circledR}$ (LOPES et al., 2002).

Os itens que compuseram o custo operacional efetivo de produção do leite foram divididos em grupos: mão de obra, alimentação, sanidade, reprodução, ordenha, impostos considerados fixos, energia e despesas diversas (LOPES; LOPES, 1999). No caso das propriedades que utilizavam hormônio BST, as despesas referentes a esse item foram alocadas no grupo sanidade, enquanto aluguel de máquinas, em despesas diversas.

Para atender os objetivos da pesquisa e obter melhor interpretação dos resultados, os sistemas de produção foram enquadrados em um de três níveis tecnológicos, considerando-se o critério capital investido na atividade leiteira, baseando-se nas informações obtidas no inventário, na sofisticação de equipamentos como, por exemplo, modelo do tanque de resfriamento de leite, e nas observações realizadas durante as visitas mensais. No nível tecnológico alto, foram enquadrados os sistemas de produção que possuíam ordenhadeira mecânica do tipo leite canalizado, altos investimentos em máquinas e implementos agrícolas e instalações sofisticadas. Nesse nível, o grupo genético dos animais foi igual ou superior a 15/16 de fração da raça Holandesa. No nível tecnológico baixo, foram enquadrados os sistemas de produção que não possuíam máquinas e implementos agrícolas e ordenhadeira mecânica e com pequeno investimento em instalações. O rebanho era composto de animais mestiços ou de grupo genético não definido. No nível tecnológico médio, foram enquadrados os sistemas de produção intermediários. 
Os seguintes indicadores foram avaliados: 1) produção diária de leite (L/dia); 2) área ocupada com a atividade leiteira (ha); 3 ) mão de obra contratada (dh - dia homem); 4) mão de obra familiar (dh); 5) quantidade de vacas em lactação (cab - cabeças); 6) taxa de lotação de vacas em lactação (cab/ha) = quantidade de vacas em lactação/área total; 7) produtividade por vaca em lactação (L/ano) = produção diária de leite/quantidade de vacas em lactação; 8) vacas em lactação por dia/homem $(\mathrm{cab} / \mathrm{dh})=$ quantidade de vacas em lactação/total de mão de obra anual; 9) produtividade da mão de obra $(\mathrm{L} / \mathrm{dh})=$ produção anual de leite/total de mão de obra anual; 10) produtividade da terra (L/ ha/ano) $=$ produção anual de leite/área ocupada com a atividade leiteira; 11) receita bruta do leite $(\mathrm{RBL})$ em relação à receita bruta total (RBT) $(\%)$ $=\mathrm{RBL} / \mathrm{RBT} \times 100 ; 12)$ representatividade do custo operacional efetivo (COE) na receita bruta total $(\%)=(\mathrm{COE} / \mathrm{RBT}) \times 100 ; 13)$ representatividade do custo operacional total (COT) na receita bruta total $(\%)=(\mathrm{COT} / \mathrm{RBT}) \times 100 ; 14) \mathrm{COE}$ unitário em relação ao preço de leite $(\mathrm{PL})(\%)=(\mathrm{COEun} /$ PL) x 100; 15) COT unitário em relação ao preço de leite $(\%)=($ COTun/PL $) \times 100 ; 16)$ custo total unitário em relação ao preço de leite $(\%)=$ (CTun/PL) x 100; 17) relação entre o custo fixo e o custo total $(\%)=(\mathrm{CF} / \mathrm{CT}) \times 100(\%) ; 18)$ representatividade da depreciação no COT $(\%)=$ (depreciação/COT) x 100; 19) lucratividade 1 (\%) $=($ resultado/receita total $) \times 100 ; 20)$ lucratividade $2(\%)=($ margem líquida/receita total $) \times 100 ; 21)$ rentabilidade $1(\%)=($ resultado/total imobilizado $)$ x $100 ; 22)$ rentabilidade $2(\%)=$ (margem líquida/ total imobilizado) x $100 ; 23)$ representatividade da alimentação no custo total $(\%)=$ (alimentação/ CT) x 100 ; 24) representatividade da mão de obra no custo total $(\%)=($ mão de obra/CT $) \times 100 ; 25)$ representatividade da sanidade no custo total (\%) $=($ sanidade $/ \mathrm{CT}) \times 100 ; 26)$ representatividade da ordenha no custo total $(\%)=($ ordenha $/ \mathrm{CT}) \times 100 ; 27)$ representatividade da reprodução no custo total (\%) $=($ reprodução/CT $)$ x 100; 28) representatividade da energia no custo total $(\%)=($ energia/CT $) \times 100$; 29) representatividade dos impostos e taxas no custo total $(\%)=($ impostos e taxas/CT $) \times 100 ; 30)$ representatividade das despesas diversas no custo total $(\%)=($ despesas diversas/CT $) \times 100 ; 31)$ representatividade da alimentação no $\operatorname{COE}(\%)=$ (alimentação/COE) x 100; 32) representatividade da mão de obra no COE $(\%)=$ (mão de obra/COE) $\mathrm{x} 100 ; 33)$ representatividade da sanidade no COE $(\%)=($ sanidade $/ \mathrm{COE}) \times 100 ; 34)$ representatividade da reprodução no COE $(\%)=($ reprodução/COE $) x$ $100 ; 35)$ representatividade da ordenha no $\mathrm{COE}$ $(\%)=($ ordenha/COE $) \times 100 ; 36)$ representatividade dos impostos e taxas no COE $(\%)=($ impostos e taxas/COE) x 100; 37) representatividade da energia no $\operatorname{COE}(\%)=($ energia $/ \mathrm{COE}) \times 100$; 38) representatividade das despesas diversas no COE $(\%)=($ despesas diversas/COE $) \times 100$. Tais indicadores foram selecionados considerando a disponibilidade de dados e a sua relevância. Para a estimação da lucratividade 1 e 2 foi considerada a metodologia proposta por Lopes et al. (2011).

Foi realizado o teste de Kolmogorov-Smirnov para avaliar a distribuição das variáveis contínuas, sendo detectado que algumas das variáveis não apresentaram distribuição normal. Os resultados foram expressos em média \pm desvio padrão (para distribuição normal) e mediana e intervalo de quartis (quando não houve distribuição normal) (DUQUIA; BASTOS, 2006). As comparações foram feitas pelo teste de ANOVA, complementadas pelo teste de Least Significant Difference (LSD) para comparações múltiplas, quando os dados apresentaram distribuição normal. Quando os dados não apresentaram distribuição normal, as comparações entre os grupos foram feitas pelo teste de Kruskal-Wallis, também complementadas pelo teste LSD para comparação múltipla entre as médias ranqueadas das variáveis. Considerou-se a diferença estatística significante quando $\mathrm{P}<0,05$. Todas as análises estatísticas adotadas foram realizadas com o auxílio do software R, versão 2.15.2. 


\section{Resultados e Discussão}

A quantidade de sistemas de produção foi de $17(27,8 \%), 32(52,5 \%)$ e $12(19,7 \%)$ para baixo, médio e alto nível tecnológico, respectivamente. A Tabela 1 apresenta os resultados referentes aos indicadores de tamanho e zootécnico das 61 propriedades leiteiras distribuídas em função do nível tecnológico. Observa-se que não houve diferença estatística significante $(\mathrm{P}>0,05)$ para os indicadores de tamanho e zootécnico entre os grupos baixo e médio nível tecnológico, com exceção do indicador área. Isso não era esperado e sugere que a estratificação dos sistemas de produção em função do nível tecnológico não foi um bom critério para ser utilizado quando se deseja realizar comparações entre grupos distintos de produtores e que outros critérios, tais como, escala de produção, poderiam ser adotados.

$\mathrm{Na}$ análise dos indicadores de tamanho e zootécnico das propriedades, foi observada normalidade apenas para o indicador PL/VL. A mediana da produção diária de leite foi de 150,7; 290,0 e 1.861,2 L para baixo, médio e alto níveis tecnológicos, respectivamente. Foi observada diferença estatística significante $(\mathrm{P}<0,05)$ para alto nível tecnológico (Tabela 1). Isso foi devido, principalmente, a maior quantidade de vacas em lactação (98,5 cabeças) e a maior produtividade por vaca $(5.894,4 \mathrm{~L} /$ vaca/ano) que caracterizaram os produtores de alto nível tecnológico participantes desta pesquisa. De acordo com Lopes (1997), algumas tecnologias facilitam o manejo e contribuem para aumentar a produtividade. Os valores da mediana obtidos nesta pesquisa para o indicador área foram de 16,$0 ; 54,0$ e 103,5 ha para baixo, médio e alto nível tecnológico, respectivamente. Houve diferença estatística significante $(\mathrm{P}<0,05)$ entre os níveis tecnológicos (Tabela 1). Tal fato denota que os produtores caracterizados por elevada adoção de capital da amostra estudada também possuíam elevado capital imobilizado em terras.

A mediana da taxa de lotação de vacas em lactação variou de 0,6 a 1,2 cab/ha e não houve diferença estatística significante $(\mathrm{P}>0,05)$ entre baixo, médio e alto níveis tecnológicos (Tabela 1).

A produtividade da mão de obra foi de 65,$1 ; 119,6$ e $307,0 \mathrm{~L} / \mathrm{dh}$ e 7,$7 ; 11,1$ e $17,9 \mathrm{cab} / \mathrm{dh}$ para baixo, médio e alto níveis tecnológicos, respectivamente. Foi observada diferença estatística $(\mathrm{P}<0,05)$ para o grupo alto nível tecnológico (Tabela 1), o que denota a otimização do seu uso, também constatada pela maior $(\mathrm{P}<0,05)$ quantidade de vacas em lactação por mão de obra. Isso pode ser explicado pelo maior capital tecnológico, como a adoção de ordenhadeira mecânica do tipo leite canalizado, máquinas e implementos agrícolas. Não obstante, esses valores foram inferiores aos relatados por Silva (2006), de $832 \mathrm{~L} / \mathrm{dh}$, e aos sugeridos por Jarret (1997), de uma relação vaca:homem de 66:1 e 111:1 para sistemas de produção com 300 e 1.000 vacas, respectivamente.

No que se refere à produtividade por área, foram observados valores de 4.512,6; 2.132,2 e 7.367,2 L/ ha/ano para baixo, médio e alto nível tecnológico, respectivamente. Não houve diferença estatística significante $(\mathrm{P}>0,05)$ entre os níveis tecnológicos (Tabela 1). 


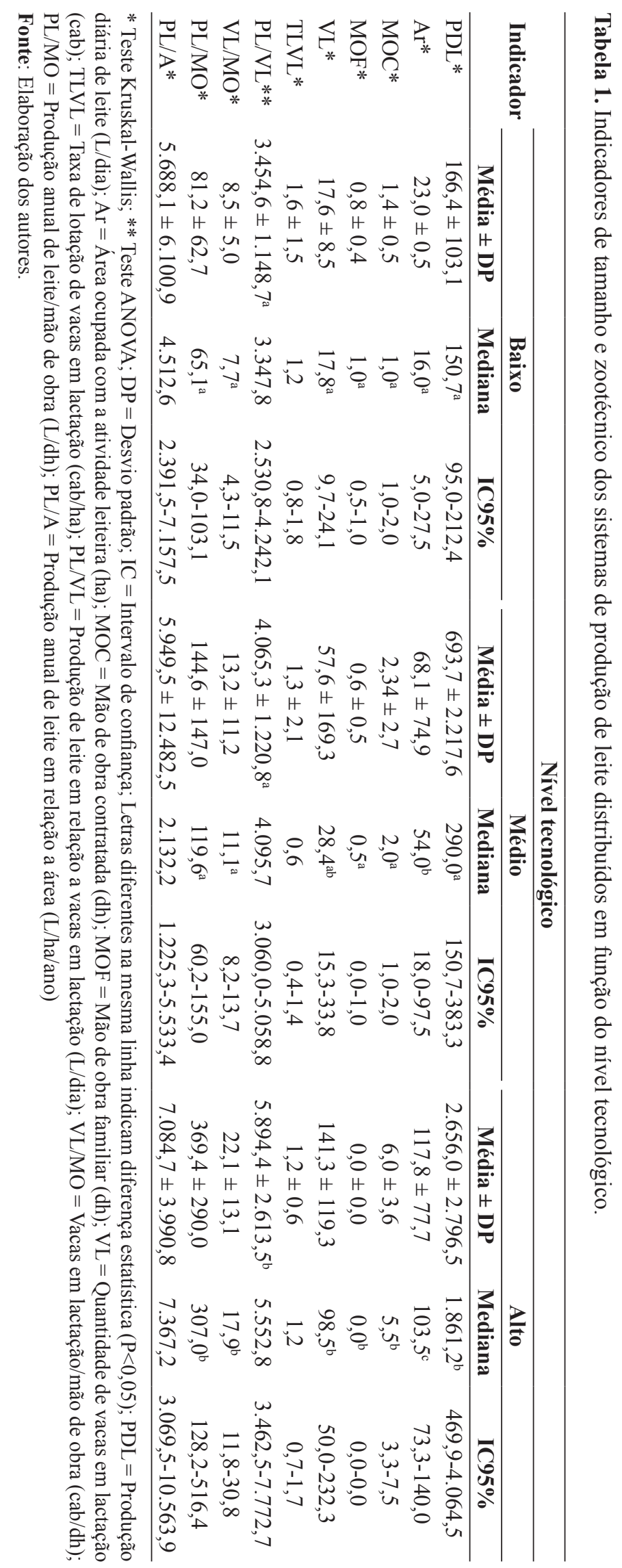


Os resultados referentes aos indicadores econômicos das propriedades leiteiras, distribuídas em função do nível tecnológico, encontramse descritos na Tabela 2. De maneira similar ao identificado na análise dos indicadores de tamanho e zootécnico, não houve diferença estatística significante $(\mathrm{P}>0,05)$ para os indicadores econômicos entre os grupos de baixo e médio nível tecnológico, com exceção da representatividade da energia no $\mathrm{CT}(\mathrm{E} / \mathrm{CT})$ e de despesas diversas no $\mathrm{COE}(\mathrm{DD} / \mathrm{COE})$ e no $\mathrm{CT}(\mathrm{DD} / \mathrm{CT})$.

A receita bruta do leite em relação à receita bruta total foi de 86,$3 ; 91,0$ e $96,8 \%$ para baixo, médio e alto nível tecnológico, respectivamente. A despeito da participação da receita bruta do leite dos produtores amostrados terem sido crescentes com o aumento do capital investido na atividade leiteira, não houve diferença estatística significante $(\mathrm{P}>0,05)$ entre os grupos (Tabela 2). Esse fato pode ser explicado pela grandeza do intervalo de confiança que caracterizou a amostra.

A participação do $\mathrm{COE}$ na receita bruta total foi de 51,6; 55,0 e 87,2\% e do COT na receita bruta total foi de 73,$4 ; 73,2$ e $94,6 \%$ para baixo, médio e alto nível tecnológico, respectivamente, sendo significativamente maior $(\mathrm{P}<0,05)$ para o nível tecnológico alto (Tabela 2). Isso já era esperado devido aos elevados gastos com alimentação, reprodução e sanidade, que compõem o $\mathrm{COE}$, e depreciação de benfeitorias, máquinas e equipamentos (COT). Essa elevada representatividade define a necessidade de ganhos em escala de produção para o grupo de produtores com alto nível tecnológico. Lopes, Reis e Yamaguchi (2007) identificaram ganhos em relação ao aumento do volume de produção e ao melhor aproveitamento dos fatores produtivos. Segundo esses autores, o custo total variou menos que proporcionalmente em relação à produção, indicando taxas de crescimento decrescentes do custo total em função do aumento no volume produzido, o que corresponde a taxas de rendimentos crescentes à escala de produção.

Foi verificado, na presente pesquisa, que o custo fixoem relação ao custo total(CF/CT) foi de 28,1;33,6 e 16,6\% para baixo, médio e alto nível tecnológico, respectivamente, sendo significativamente menor $(\mathrm{P}<0,05)$ para o grupo alto nível tecnológico (Tabela 2). Tal fato pode ser explicado pela elevada contribuição do custo variável e, consequentemente, atenuação da participação do custo fixo. De fato, conforme apontado por Marques et al. (2002), os produtores com maior escala de produção apresentam uma relação $\mathrm{CF} / \mathrm{CT}$ expressivamente mais baixa. De maneira similar, também foi verificado que a depreciação em relação ao COT foi significativamente menor $(\mathrm{P}<0,05)$ para o grupo alto nível tecnológico. O melhor aproveitamento da capacidade produtiva da instalação, evitando a sua ociosidade, é recomendável por permitir ao pecuarista "diluir" seus custos e buscar eficiência técnica, administrativa e econômica.

A lucratividade consiste em estabelecer um índice percentual para representar o lucro obtido na atividade. Ela é utilizada para comparar atividades iguais, a fim de se conhecer qual é a mais lucrativa. Já a rentabilidade mede a capacidade da atividade de gerar rendimentos em relação ao capital total disponível, demonstrando uma relação percentual entre o lucro e esse capital. Ela é utilizada para comparar atividades diferentes a fim de verificar qual das atividades possui melhor desempenho econômico. Nesta pesquisa, a lucratividade 1 foi de 0,$6 ; 1,5$ e $-8,5 \%$, enquanto que, a rentabilidade 1 foi de 0,$2 ; 0,4$ e $-2,4 \%$ para baixo, médio e alto nível tecnológico, respectivamente, sem, contudo, haver diferença estatística significante $(\mathrm{P}>0,05)$ para lucratividade 1 e rentabilidade 1 entre os grupos estudados (Tabela 2). 


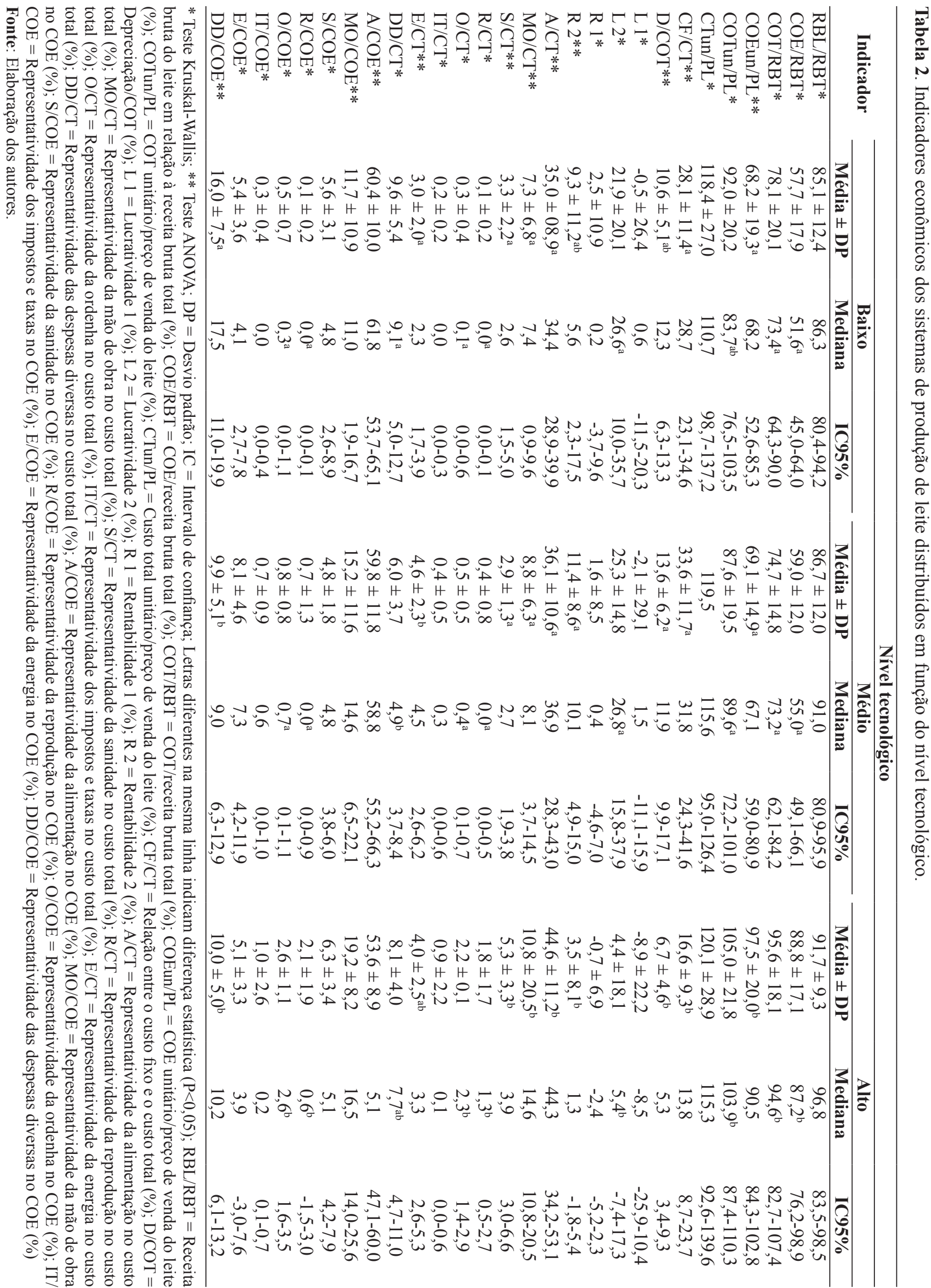


Para o cálculo da lucratividade 1 e rentabilidade 1 leva-se em consideração o resultado da atividade, já estando imputado a remuneração do capital e da terra. Visando maior clareza na análise dos resultados foi considerada ainda a lucratividade 2 e rentabilidade 2 , que consistem no uso da margem líquida, ao invés do lucro líquido (LOPES et al., 2011). Ao considerar a margem líquida (Receita - Custo operacional total), o valor obtido poderá ser comparado com a caderneta de poupança, por exemplo, ou qualquer outra aplicação, conferindo maior poder de comparação. No presente estudo, a lucratividade 2 foi de 26,$6 ; 26,8$ e 5,4\% para baixo, médio e alto nível tecnológico, respectivamente, sendo significativamente menor $(\mathrm{P}<0,05)$ para os produtores de alto nível tecnológico. A rentabilidade 2 representou 9,3; 11,4 e 3,5\% para os grupos baixo, médio e alto nível tecnológico, diferindo estatisticamente $(\mathrm{P}<0,05)$ apenas entre médio e alto nível tecnológico (Tabela 2). A análise desses resultados permite inferir que, nesta amostra, os produtores de baixo e médio nível tecnológico obtiveram melhores resultados econômicos e que a rentabilidade daqueles de alto nível tecnológico foi menos atrativa do que a da caderneta de poupança ( $6 \%$ a.a.). Seria esperado, no entanto, que o maior capital investido na atividade em terra, benfeitorias, máquinas, implementos, animais e manejo pelos produtores caracterizados com alto nível tecnológico gerassem melhores resultados econômicos, conforme relatado por Schiffler et al (1999). Concordando com os achados deste estudo, a análise de produtores de leite localizados no estado de Minas Gerais, revelou que os produtores menos eficientes apresentaram investimentos em máquinas e terra além do necessário para o nível de produção observado (FERREIRA, 2002), o que demonstra que os sistemas de produção menos tecnificados, embora tenham apresentado menor produtividade, apresentaram custos mais baixos e foram mais rentáveis (HOLANDA JÚNIOR; MADALENA, 1998).
A divisão das despesas em grupos, de acordo com Lopes e Lopes (1999) permite o monitoramento das despesas do sistema de produção de leite, auxiliando o técnico e o produtor em uma análise mais detalhada. Dessa forma, optou-se em dividir as despesas nos seguintes grupos: alimentação, mão de obra, sanidade, reprodução, ordenha, impostos considerados fixos e taxas, energia e despesas diversas.

A alimentação teve um impacto maior e representou 60,$4 ; 59,8$ e $53,6 \%$ do $\mathrm{COE}$ e 35,0 ; 36,1 e 44,6\% do CT para baixo, médio e alto nível tecnológico, respectivamente. Todos os sistemas de produção utilizaram suplementação com concentrado durante todo o ano e suplementação com volumoso e concentrado na seca. O alto percentual nos sistemas de baixo nível tecnológico pode ser explicado pela pequena contribuição dos demais itens componentes do $\mathrm{COE}$, como mão de obra, reprodução e ordenha. No entanto, apesar de numericamente superior para os produtores de baixo nível tecnológico amostrados, não houve diferença estatística significante $(\mathrm{P}>0,05)$ para o $\mathrm{COE}$, enquanto que, quando considerado o CT, os produtores de alto nível tecnológico diferiram significativamente $(\mathrm{P}<0,05)$ dos demais grupos. Comportamento semelhante foi observado para representatividade da mão de obra no $\mathrm{COE}$, não apresentando diferença estatística significante $(\mathrm{P}>0,05)$ entre os grupos, e sendo significativamente maior $(\mathrm{P}<0,05)$ para o grupo alto nível tecnológico, quando considerado o CT (Tabela 2).

Os componentes do $\mathrm{COE}$ reprodução e ordenha representaram 0,$0 ; 0,0$ e $0,6 \%$ e 0,$3 ; 0,7$ e 2,6\% para baixo, médio e alto nível tecnológico, respectivamente, e foram significativamente maiores $(\mathrm{P}<0,05)$ para o grupo alto nível tecnológico. Resultados semelhantes foram observados para esses dois itens, quando considerado o CT (Tabela 2). Tal fato pode ser explicado devido ao uso de inseminação artificial e ordenhadeira mecânica. Além disso, o grupo de alto nível tecnológico se 
constitui de produtores com maiores quantidades de vacas em lactação e volume de produção diário e que buscam excelência produtiva, priorizando práticas de higiene e qualidade do leite. Outra justificativa inclui a associação relatada na literatura entre a alta produção de leite por vaca (característica de rebanhos de alto nível tecnológico) e a baixa eficiência reprodutiva. Isso ocorre devido a alterações na fisiologia reprodutiva (SANGSRITAVONG et al., 2002; WILTBANK et al., 2006) e ao tamanho do rebanho, que pode comprometer as práticas operacionais individuais da fazenda (WILTBANK et al., 2006), como a observação de cio, resultando no aumento da repetição de cios e no uso de programas reprodutivos intensivos, como a inseminação artificial em tempo fixo (IATF). Consequentemente, os gastos com insumos referentes a esse grupo de despesa, como por exemplo, doses de sêmen e hormônios, tendem a serem aumentados.

\section{Conclusões}

Índices de medição de desempenho de referências devem ser considerados levando-se em conta os fatores que sejam comuns aos sistemas de produção, com objetivo de gerar parâmetros mais precisos para a atividade leiteira, considerando a grande heterogeneidade da mesma no território brasileiro. No entanto, a estratificação dos sistemas de produção em função do nível tecnológico pode não é um bom critério para ser utilizado quando se deseja realizar comparações entre grupos distintos de produtores.

A estimativa de índices de desempenho zootécnico e econômico, como instrumento de rotina, é uma ferramenta gerencial imprescindível para verificar a viabilidade operacional e econômica do sistema de produção e fornecer com acurácia as informações necessárias para o planejamento e a tomada de decisão. Os produtores de alto nível tecnológico fazem investimentos sem as devidas análises de retorno sobre o investimento e risco. Os itens componentes do custo total e operacional efetivo que exercem maiores representatividades são, em ordem decrescente, alimentação e mão de obra.

\section{Agradecimentos}

Os autores agradecem à Fundação de Amparo à Pesquisa do Estado de Minas Gerais (FAPEMIG) pelo apoio recebido para a realização desta pesquisa (SHA APQ 01974/11).

\section{Referências}

CARMO, M. S. A produção familiar como locus ideal da agricultura sustentável. Agricultura em São Paulo, São Paulo, v. 45, n. 1, p. 1-15, 1998.

DUQUIA, R. P.; BASTOS, J. L. D. Medidas de tendência central: onde a maior parte dos indivíduos se encontra? Scientia Medica, Porto Alegre, v. 16, n. 4, p. 190-194, 2006.

FERREIRA, A. H. Eficiência de sistemas de produção de leite: uma aplicação da análise envoltória de dados na tomada de decisão. 2002. Dissertação (Mestrado em Economia Aplicada) - Universidade Federal de Viçosa, Viçosa.

FERREIRA, M. M.; FERREIRA, A. C. M.; EZEQUIEL, J. M. B. Avaliação econômica da produção de bovinos confinados: estudo de caso. Informações Econômicas, São Paulo, v. 34, n. 7, p.7-20, 2004.

FIGUEIREDO, A. M.; GOMES, A. L. Considerações sobre estratificação de produtores de leite em Minas Gerais. In: CONGRESSO DA SOCIEDADE BRASILEIRA DE ECONOMIA, ADMINISTRAÇÃO E SOCIOLOGIA RURAL, 47., 2009, Porto Alegre. Anais... Brasília: SOBER, 2009. p. 1-11.

GOMES, A. P.; ALVES, E. Identificando ineficiências na produção de leite. Boletim do Leite, Piracicaba, v. 6, n. 66, p. 1-2, 1999.

HADDADE, I. R.; SOUZA, P. M.; BARROS, E. E. L.; ALVES, G. R.; SCOLFORO, L.; CORDEIRO, M. D.; PERES, A. A. C.; HENRIQUES, L. T. Avaliação econômica sob condições de risco em sistema produtivo de gado de leite na região Norte do estado do Rio de Janeiro. Arquivo Brasileiro de Medicina Veterinária e Zootecnia, Belo Horizonte, v. 57, n. 3, p. 361-366, 2005.

HOLANDA JÚNIOR, E. V.; MADALENA, F. E. Leite caro não compensa. Caderno Técnico da Escola de Veterinária, Belo Horizonte, n. 25, p. 13-18, 1998. 
JARRET, J. Produção de leite de qualidade. In: SIMPÓSIO INTERNACIONAL SOBRE PRODUÇÃO INTENSIVA DE LEITE, 3., 1997, Belo Horizonte. Anais... Belo Horizonte: FMVZ, 1997. p. 34-45.

LOPES, M. A. Informática aplicada à bovinocultura. Jaboticabal: Funep, 1997. 82 p.

LOPES, M. A.; CAMPELlO, R. P.; CARVALHO, F. M.; LOPES, D. C. F. Custo bovino leite 1.0: software de controle de custos para a atividade leiteira. Revista Brasileira Agroinformática, Viçosa, v. 4, n. 2, p. 102115, 2002.

LOPES, M. A.; LIMA, A. L. R.; CARVALHO, F. M.; REIS, R. P.; SANTOS, I. C.; SARAIVA, F. H. Controle gerencial e estudo da rentabilidade de sistemas de produção de leite na região de Lavras (MG). Revista Ciência e Agrotecnologia, Lavras, v. 28, n. 4, p. 883-892, 2004.

LOPES, M. A.; LOPES, D. C. F. Desenvolvimento de um sistema computacional para cálculo do custo de produção do leite. Revista Brasileira de Agroinformática, Lavras, v. 2, n. 1, p. 1-12, 1999.

LOPES, M. A.; SANTOS, G.; RESENDE, M. C.; CARVAlHO, F. M.; CARDOSO, M. G. Estudo da rentabilidade de sistemas de produção de leite na região de Nazareno (MG). Ciência Animal Brasileira, Goiânia, v. 12, n. 1, p. 58-69, 2011.

LOPES, P. F.; REIS, R. P.; YAMAGUCHI, L. C. T. Custos e escala de produção na pecuária leiteira: estudo nos principais estados produtores do Brasil. Revista de Economia e Sociologia Rural, Brasília, v. 45, n. 3, p. 567-590, 2007.
MADALENA, F. E. A vaca econômica. In: ENCONTRO DE PRODUTORES DE F1 - JORNADA TÉCNICA SOBRE UTILIZAÇÃO DE F1 PARA PRODUÇÃO DE LEITE, 3., 2001, Juiz de Fora. Anais... Juiz de Fora: Embrapa/CNPGL, 2001. p. 9-16.

MARQUES, V. M.; REIS, R. P.; SÁFADI, T.; REIS, A. J. Custos e escala na pecuária leiteira: estudo de casos em Minas Gerais. Ciência e Agrotecnologia, Lavras, v. 26, n. 5, p. 1027-1034, 2002.

SANGSRITAVONG, S.; COMBS, D. K.; SARTORI, R.; ARMENTANO, M. C.; WILTBANK, M. C. High feed intake increases blood flow and metabolism of progesterone and estradiol-17ß in dairy cattle. Journal of Dairy Science, Madison, v. 85, n. 11, p. 2831-2842, 2002.

SCHIFFLER, E. A.; MÂNCIO, A. B.; GOMES, S. T.; QUEIROZ, A. C. Efeito da escala de produção nos resultados econômicos da produção de leite B no Estado de São Paulo. Revista Brasileira de Zootecnia, Viçosa, v. 28, n. 2, p. 425-431, 1999.

SILVA, H. A. Resultados econômicos de sistemas de produção de leite com diferentes níveis tecnológicos na Cooperativa Agropecuária Castrolanda, Castro, PR. In: CONGRESSO PAN-AMERICANO DO LEITE, 9., 2006, Porto Alegre. Anais... Porto Alegre: Embrapa, 2006. CD-ROM.

TUPY, O.; FREITAS, A. R.; ESTEVES, S. N.; SCHIFFER, E. A.; VIEIRA, M. C. Eficiência econômica na produção de leite tipo B no estado de São Paulo. Informações Econômicas, São Paulo, v. 33, n. 2, p. 14-20, 2003.

WILTBANK, M.; LOPEZ, H.; SARTORI, R.; SANGSRITAVONG, S.; GÜMEN, A. Changes in reproductive physiology of lactating dairy cows due to elevated steroid metabolism. Theriogenology, Philadelphia, v. 65, n. 1, p. 17-29, 2006. 
